http://dx.doi.org/10.30681/23588403v12i01105120

\title{
O GUIA LITERATURA NA HORA CERTA E A FORMAÇÃO DOCENTE: CONTRIBUIÇÕES PARA O LETRAMENTO LITERÁRIO
}

Data de recebimento: 03/11/2017

Aceite: 11/12/2017

\author{
Elza Rodrigues Barbosa PEIXOTO (UFT) ${ }^{1}$ \\ Maria José de PINHO(UFT) ${ }^{2}$
}

\begin{abstract}
Resumo: Este artigo discute e analisa, pela perspectiva do letramento, a ação de formação do professor alfabetizador trazida pelo PNLD/PNAIC na edição 2015, através do Guia de Literatura na Hora Certa. Nosso foco é o tratamento dado ao texto literário na fase de alfabetização, que tem o guia como seu primeiro "caderno de formação" específico para professores das séries iniciais. Algumas indagações suscitaram esse trabalho: Por quais rumos caminha a abordagem dada ao texto literário na formação do professor alfabetizador, dentro de um dos mais abrangentes programas de formação continuada, o Pnaic? Quais concepções assumem no trabalho com a leitura literária no ciclo de alfabetização? A proposta apresentada no Guia Literatura na Hora Certa segue quais rotas, trazem contribuições para o letramento do professor? Evidenciou-se, pela análise empreendida, a importância de marcar as séries iniciais como a hora certa da literatura revelando que os guias se apresentaram como uma oportunidade ímpar de sanar a falta de uma formação específica ao docente alfabetizador.

Palavras-chave: Leitura, alfabetização, letramento literário.
\end{abstract}

Abstract: On this paper, we talk and analyze, from the perspective of literacy, the training action of the literacy worker, brought by the PNLD/PNAIC in the 2015 edition, through the Literature Guide at the Right Time. Our focus is the treatment given to the literary text in the literacy phase, which has the guide as its first "training book" specific to teachers in the initial grades. Some questions raised this work: In what direction does the approach given to the literary text in the formation of the literacy teacher, within one of the most comprehensive continuing education programs, the PNAIC? What are the conceptions of literary reading that they assume? Which perspective does Literature Guide at Right Time present? Do they contribute to the teacher's literacy? . It was evident, by the analysis undertaken, through the analysis undertaken, the importance of marking the initial grades as the right time of the literature revealing that the guides presented themselves as a unique opportunity to remedy the lack of specific training for the literacy teacher.

Keywords: Reading, literacy, literary literacy

\section{Considerações iniciais}

A proposição deste artigo se justifica e se organiza a partir de duas questões de base importantes de serem discutidas no atual cenário educacional brasileiro. Uma diz respeito ao papel da literatura em sala de aula na formação do leitor; a outra questão se refere à Literatura na alfabetização. Essas questões estão ligadas, nesse

\footnotetext{
${ }^{1}$ Doutoranda em Letras Ensino de Língua e Literatura da Universidade Federal do Tocantins.

Araguaína, Tocantins. e-mail: elza.peixoto21@gmail.com.

${ }^{2}$ Doutora. Universidade Federal do Tocantins. Araguaína, Tocantins. e-mail:mjpgon@uft.edu.br.
} 


\section{Revista de Estudos Acadêmicos de Letras}

estudo, pelo Pacto Nacional de Alfabetização na Idade Certa (doravante PNAIC), edição 2015, em sua proposta de formação de professores, organizada no formato de guias, manuais que acompanham o acervo selecionado de literatura que é distribuído pelo governo federal às escolas cadastradas no referido programa.

Desse cruzamento de bases nascem as reflexões que aqui nos propusemos a fazer: Por quais rumos caminha a abordagem dada ao texto literário na formação do professor alfabetizador, dentro de um dos mais abrangentes programas de formação continuada, o Pnaic? Quais concepções assumem no trabalho com a leitura literária no ciclo de alfabetização? A proposta apresentada no Guia Literatura na Hora Certa segue quais rotas, trazem contribuições para o letramento do professor?

Essas foram as indagações motivadoras deste trabalho que tem como objetivo ampliar as reflexões sobre leitura literária na alfabetização, analisando as abordagens trazidas na ação de formação do professor proposta pelo Guia de Literatura na Hora Certa. Nosso foco é o tratamento dado ao texto literário na fase de alfabetização, que tem o guia como seu primeiro "caderno de formação" específico para professores das séries iniciais, lançado pelo PNLD/PNAIC, na edição 2015. A pertinência em trazer esse tema à discussão justifica-se, primeiro, por reconhecermos a alfabetização como um dos momentos cruciais nos processos de letramento; depois, porque parece que muitos professores têm se "esquecido" ou "deixado de lado" o verdadeiro potencial da literatura a ser explorado nessa fase de formação do pequeno leitor, "acomodados" a um modelo pragmático e utilitarista do texto literário como checagem de decodificação de leitura.

Nesse sentido, para cumprir os objetivos deste estudo, tomou-se como corpus de análise os volumes 1, 2 e 3 do Guia de Literatura na Hora Certa- 2015 (PNLD/PNAIC), correspondentes aos três anos iniciais do ensino fundamental. A análise se fundamenta nos estudos do letramento, especificamente o literário.

Para melhor circunscrever o objeto de estudo dentro do seu panorama geral, buscou-se, inicialmente, uma breve contextualização da formação em Língua Portuguesa do professor alfabetizador, a partir da abordagem teórico-metodológica 


\section{Revista de Estudos Acadêmicos de Letras}

trazida pelo PNAIC (2013), contando também com algumas incursões a estudos recentes que tratam da abordagem dada pelo Pacto à literatura, até a inserção, em 2015, do Guia de Literatura na Hora Certa, disponibilizado pelo Ministério da Educação e Secretaria de Educação Básica MEC/SEB, como "apoio pedagógico ao processo de introdução das crianças à cultura do escrito", distribuídos junto com os acervos especificamente selecionados para as salas de aula dos três anos iniciais do ensino fundamental pelo PNLD/PNAIC ${ }^{1}$. Num segundo momento procuramos estabelecermos algumas reflexões sobre o papel da literatura em sala de aula e conexões entre as análises realizadas, tendo como suporte os discursos teóricos que tratam da "adequada" escolarização da leitura e literatura e o letramento literário.

\section{O lugar da literatura no pacto nacional de alfabetização na idade certa}

O PNAIC foi instituído no ano de 2012 pelo Ministério da Educação (BRASIL, 2012a; 2012b; 2012c) e implementado por todo o país em 2013, por meio de acordo formal feito entre governo federal, estados, municípios e entidades, com o objetivo de alfabetizar todas as crianças até oito anos de idade. É composto sob quatro eixos de atuação: formação continuada de professores alfabetizadores; elaboração e distribuição de materiais didáticos e pedagógicos; avaliações e gestão, controle social e mobilização.

No eixo da formação, o objetivo proposto pelo programa tem visado, conforme exposto em seus documentos, a formação de educadores críticos, que proponham soluções criativas para os problemas enfrentados pelas crianças em processo de alfabetização. Esse item se completa no eixo de materiais didáticos, com obras literárias e de apoio pedagógico, além de jogos e tecnologias educacionais, numa junção de elementos que estruturam e dão suporte às formações oferecidas. Apresentado como referência o Decreto n 6.094, de 24 de abril de 2007, a Portaria

\footnotetext{
${ }^{1}$ Esse material consta como compromisso formal do Ministério da Educação para o cumprimento da meta 5 do PNE- Plano Nacional de Educação (2014-2020) e é parte do PNLD- Plano Nacional do Livro Didático do PNAIC.
} 


\section{Revista de Estudos Acadêmicos de Letras}

nº67, de 4 de julho de 2012 e marca presença também na Meta 5 do Plano Nacional de Educação (PNE - Lei no 13.005/2014).

O pacto vem, juntamente com o Plano Nacional de Biblioteca Escolar PNBE, ampliar o programa de distribuição de acervo literário. O diferencial é que seu acervo não se destina às bibliotecas, os kits do Acervo Complementar são de "uso coletivo em sala de aula". É importante destacar que somente as distribuições dos livros não sanam os problemas com a leitura, nem a presença simples do livro fará por si só a condução ou encantamento da leitura literária, constatação que coloca em evidência a figura do professor como peça fundamental, mas, para cumprir essa função, antes é preciso que seja um professor leitor.

Quanto mais evidente ficar para o professor a importância da leitura literária como poderosa fonte de formação de sensibilidades e de ampliação de nossa visão de mundo, que tem nessa linguagem artística um componente essencial de formação, culturalmente valorizado (embora pouco demandada e pouco ofertada socialmente), mais significativas se tornarão as práticas de letramento literário propostas. Isso tudo se, primeiro, o professor se conhecer como sujeito-leitor e souber dimensionar suas práticas de leitura, especialmente a literária. (PAIVA, 2008, p. 116).

Ao longo das etapas de formação do PNAIC, a importância dada à formação do professor/leitor literário esteve marcada nos encontros de formação, sendo a literatura parte permanente de todo processo, como por exemplo, a Leitura Deleite, atividade com a qual todos os encontros eram iniciados, colocada em prática a "leitura de textos literários, com conversa sobre os textos lidos, incluindo algumas obras de literatura infantil, com o intuito de evidenciar a importância desse tipo de atividade" (BRASIL, 2012, p.32).

Korn e Koerner (2016) realizaram, recentemente, um estado da arte das produções científicas sobre o pacto Nacional da Alfabetização na Idade Certa entre 2013 e 2016. A investigação teve como lócus específicos, as bases de dados da Coordenação de Aperfeiçoamento de Pessoal de Nível Superior (CAPES) e a Biblioteca Digital Brasileira de Teses e Dissertações (BDTD), na Associação Nacional de pós-graduação e Pesquisa em Educação (ANPEd), na Biblioteca Eletrônica Cientifica Online (SCIELO), nos Anais do XII Congresso Nacional de 


\section{Revista de Estudos Acadêmicos de Letras}

Educação (EDUCERE) e nos Anais da Associação Brasileira de Alfabetização (ABALF) cujo levantamento contribuiu como ponto de partida para nossa investigação por estudos que abordassem especificamente a leitura literária no PNAIC que contemplassem alguma relação com a formação docente. Encontramos alguns trabalhos que apontam importantes reflexões sobre a abordagem dada à literatura na etapa de formação de Língua Portuguesa (2013).

Importante observar que, dos estudos que se aproximaram da abordagem pretendida, um elemento comum figurou como destaque: a estratégia utilizada nos encontros de formação: a leitura deleite.

Souza (2016, p.9) em seu artigo discute sobre a leitura literária e a importância das políticas públicas na ampliação da compreensão leitora das crianças, apresenta como positiva a estratégia de formação do professor para as competências leitoras através da leitura deleite. Considerou essa estratégia, além de muito interessante, "um espaço para autonomia e autoria do professor e que favorece o respeito aos interesses e necessidades linguísticas e culturais dos alunos"

Domingues (2014, p. 125), em seu relato de experiência como formadora do PNAIC 2013, pontua que o programa "tem oportunizado aos professores uma experiência ímpar, pois a organização dessa formação está planejada para dar voz ao professor"; além disso, ressalta a importância dada à Literatura que constituiu "um diferencial" do programa, considerando as "possibilidades de potencializar a formação dos professores para a abordagem da literatura em sala de aula". Ainda registrando suas impressões, Domingues aponta que "o PNAIC veio para romper com uma realidade instituída nas escolas públicas de que a literatura não é significativa", ou não se tinha acesso a ela, ao menos a realidade do acervo estava transformada e a formação estava fazendo a outra parte: "As crianças leem mais, tanto para si quanto para a turma"(...) ressaltando o uso de textos literários com significado, encantamento e que garantem a possibilidade de um trabalho interdisciplinar (DOMINGUES, 2014, p.128). 


\section{Revista de Estudos Acadêmicos de Letras}

Bazzo (2014a, 2014b) discute o tema em dois estudos, e, embora avalie de forma positiva a formação literária do professor através das experiências compartilhadas e da leitura deleite, aponta para uma preocupação com os riscos ou as limitações que possam ser possibilitadas pelo reducionismo da simples reprodução das experiências relatadas nos Cadernos de formação do PNAIC, de 2013 e 2014, sem qualquer reflexão crítica.

Realmente, não há como se descartar os riscos apontados por Bazzo que são deveras significativos, tanto que o próprio caderno de formação traz como reflexão que "[...]a prática de sala de aula pode revelar e suscitar elementos que levam os professores a se verem em determinadas situações e a redirecionarem seus próprios gestos em outras situações semelhantes" (BRASIL, 2012, p. 13), e ainda propõe que, a partir dessa percepção, assumam com outro foco suas "responsabilidades" como "mediadores" de leitura e escrita, "mediadores entre a criança e o livro" (BRASIL, 2012, p. 13).

Fora o perigo da reprodução reducionista, ainda temos que considerar como desafiador o fato que a maioria dos professores alfabetizadores investem em sua missão de formação escolar do leitor literário, em sua maioria, sem formação literária suficiente. Temos que ter em mente que esse fato, por um lado, aumenta a importância de programa de formação em serviço com essa especificidade; e, por outro, a responsabilidade de encontrar uma metodologia que não privilegie modelos formatados, nem discursos reducionistas apresentados nas propostas, mas formar, ou ao menos fomentar, uma discussão da leitura literária significativa, que leve tanto alunos como professores ao letramento literário. Só para constar, o que aqui consideramos formação literária respaldamos em Paulino:

A formação de um leitor literário significa a formação de um leitor que saiba escolher suas leituras, que aprecie construções e significações verbais de cunho artístico, que faça disso parte de seus fazeres e prazeres. Esse leitor tem de saber usar estratégias de leitura adequadas aos textos literários, aceitando o pacto ficcional proposto, com reconhecimento de marcas linguísticas de subjetividade, intertextualidade, interdiscursividade, recuperando a criação de linguagem (PAULINO, 2004, p.56) 


\section{Revista de Estudos Acadêmicos de Letras}

É importante destacar que a formação do PNAIC para alfabetizadores não tinha a literatura como elemento direto de estudo até 2015, mesmo assim, como foi tratado anteriormente, através da "estratégia" da leitura deleite procurou marcar sua concepção de leitura literária como a leitura de fruição, demarcando um lugar de significativa importância no contexto de alfabetização e letramento.

Já em sua etapa mais recente, a perspectiva de um trabalho efetivo com o texto literário em sala de aula se tornou mais direto e sistematizado. Embora não tenha feito parte dos cadernos de formação ${ }^{1}$, que em 2015 estiveram centrados nas questões da interdisciplinaridade, a ação visou com uma só "caixa" realizar três "desejos": primeiro, ampliação de acervo literário para criar uma biblioteca fixa e acessível para as crianças e o professor dentro própria sala de aula; segundo, subsidiar, por meio de um guia de literatura, o saber-fazer do professor, com objetivo de potencializá-lo como mediador entre o livro e o pequeno leitor; e, por último, mas não menos importante, promover de modo "adequado" o processo de escolarização da literatura infantil, considerando a infância o melhor momento para favorecer o letramento literário das crianças.

De modo similar aos guias que compõem o $\mathrm{PNBE}^{2}$, o acervo distribuído foi dividido em três categorias: primeira: textos em verso - tais como quadra, parlenda, cantiga, trava-língua, poema, adivinha; segunda categoria: textos em prosa - tais

\footnotetext{
${ }^{1}$ A opção estratégica de não fazer parte dos cadernos de formação e sim participar como guia nas caixas de livros, segue a estratégia semelhante à realizada em 2014, na distribuição de livros do PNBE, com o PNBE NA ESCOLA Literatura fora da caixa - Guia 2, destinado aos anos iniciais do ensino fundamental. É claro que ainda não se pode mensurar se há ganho ou perda com essa estratégia, cabendo nessa linha uma outra investigação, visto que é um longo trajeto que esse material percorre até realmente chegar na escola, e, ainda assim não se sabe os procedimentos realizados na recepção desses materiais pela escola, nem o tratamento dado ao guia, depois de aberta a caixa. Por outro lado, se fizesse parte dos cadernos de formação, haveria uma certa "garantia" que esse material seria discutido em encontros de formação, mas ficaria igualmente sem garantias de ser efetivado como linha de trabalho em sala de aula, posto que esse professor/destinatário precisa ser modalizado a crer nesse saber que está sendo posto para que ele realize sua performance. Todo material de formação do PNAIC está disponível no portal do Mec, incluindo os Guias de literatura na hora certa que são nosso objeto neste trabalho.

${ }^{2}$ Esses guias e os acervos distribuídos em parceria PNLD/PNAIC seguem na linha de ação formativa das publicações PNBE na escola: Literatura fora da caixa, organizados também em três volumes distribuídos com acervos para biblioteca, porém tendo como público a Educação Infantil, o Ensino Fundamental e a Educação de Jovens e Adultos (EJA).
} 


\section{Revista de Estudos Acadêmicos de Letras}

como clássicos da literatura infantil, pequenas narrativas, textos de tradição popular, fábulas, lendas e mitos; e terceira categoria: livros ilustrados e/ou livros de imagens. Cada caixa de livros contém 35 títulos das três categorias. Os acervos são acompanhados dos Guias Literatura na Hora Certa: 1, 2 e 3, destinados à apresentação do processo de avaliação e seleção das obras e ao apoio pedagógico no uso criativo das obras distribuídas no âmbito das ações do PNAIC.

Da mesma forma na sala de aula, nos "cantinhos da leitura" (ou outras formas que a criatividade dos professores produzirem) contando com uma diversidade de gêneros literários sempre à mão "para que as crianças tenham liberdade para manipulá-los, folheá-los, confrontar temas, gêneros, dimensões, número de páginas"; e que da mesma maneira o leitor-professor " possa ter ali, em sua sala, o livro que quer ler para as crianças, que quer discutir com as crianças, que quer usar para atividades de alfabetização e letramento" (BRASIL, 2015, p.14).

Nessa relação estreita com acervo de qualidade literária, trabalhando de forma lúdica e prazerosa com as crianças, demarca-se não apenas o lugar da literatura, como todo o cenário projetado pelo discurso da proposta, vislumbrando as possibilidades dessa ação e todo seu potencial para formar leitores desde pequenos. No entanto, para que isso aconteça, não se pode perder de vista que é fundamental a mediação do professor na introdução dessas crianças ao mundo da escrita, pela arte, pois, conforme salienta Aguiar (2006, p.254), "[...] através do caráter lúdico da literatura, o entendimento do leitor alastra-se para além dos sentidos do texto", experiência que permite a compreensão do mundo em que vive, possibilitando a construção de seu próprio conhecimento.

\section{LITERATURA NA HORA CERTA, UM GUIA PARA O LETRAMENTO LITERÁRIO?}

Quando se fala em letramento literário, convém sempre refletir sobre sua relação de base com o letramento, ou sua vertente cada vez mais comum "letramentos". As diversas possibilidades adquiridas pelos sujeitos de participar de modo competente de práticas sociais também diversas. Então, poderíamos tratar o 


\section{Revista de Estudos Acadêmicos de Letras}

letramento literário, conforme Souza e Cosson (2011, p.102), como "demanda de um processo educativo específico que a mera prática de leitura de textos literários não consegue sozinha efetivar", posto que trata de um modo muito singular de construir sentidos pela linguagem literária.

Dessa forma,

[...] é importante compreender que o letramento literário é bem mais do que uma habilidade pronta e acabada de ler textos literários, pois requer uma atualização permanente do leitor em relação ao universo literário. Também não é apenas um saber que se adquire sobre a literatura ou os textos literários, mas sim uma experiência de dar sentido ao mundo por meio de palavras que falam de palavras, transcendendo os limites de tempo e espaço. (COSSON, 2011, p.102)

Assim, a responsabilidade de sistematizar esse processo recai sobre a agência de letramento por excelência, a escola, e seu principal agente, o professor. Nesse sentido, em consonância com Soares (2001, p.47), é “inevitável” que se escolarize a literatura. Então, há a imprescindível necessidade de fazer o uso adequado do texto literário, respeitando sua função estética e evitando a postura de escolarização que "deturpa, falsifica, distorce a literatura", posturas que, muitas vezes, mais afastam que aproximam o aluno da leitura literária, ou que promovem nele "resistência ou aversão ao livro e ao ler".

Abordar o letramento literário, certamente, é parte integrante e relevante das discussões sobre o processo de escolarização da literatura. Nesta seara, Evangelista (2006, p.47-48) defende que a escolarização adequada é aquela que conduz "eficazmente às práticas de leitura literária que ocorrem no contexto social e às atitudes e valores próprios do ideal que se quer formar”, cuja grande questão que está posta na relação escola e literatura é como realizá-la adequadamente. Sendo assim, o acesso a obras de qualidade já seria um passo, estabelecendo um contato, propiciando um vínculo como texto literário. (PAULINO; COSSON, 2009, p.74).

Nesse ponto, vale trazer à cena o discurso oficial de apresentação do guia, ao qual empreendemos análise, marcado por um desejo de que educadores "dedicados" aos processos de alfabetização e letramento "usufruam das obras 


\section{Revista de Estudos Acadêmicos de Letras}

selecionadas, com as crianças", com vistas ao "incentivo ao gosto literário, à imaginação, à ampliação das referências culturais e às formas - plurais e diversas de leitura das palavras, das imagens e dos símbolos, por meio da leitura do mundo" (BRASIL, 2015, p.7).

Observamos que, em discurso, os propósitos se coadunam; no entanto, outra questão se apresenta: a necessidade de termos em salas de aula de todo o país "educadores dedicados", que sejam leitores e mediadores de leitura dos pequenos iniciantes, que realmente sejam leitores e usufruam dos livros com as crianças, pois conforme Zilberman (2012, p.130)

O letramento literário se efetiva quando acontece o relacionamento entre um objeto material, o livro, e aquele universo ficcional, que se expressa por meio de gêneros específicos- a narrativa e a poesia, entre outros - a que o ser humano tem acesso graças a audição e à leitura.

Então, podemos considerar a proposta do guia como recurso formativo necessário ao letramento do professor alfabetizador, uma vez que

[...] o formador de leitor, dadas as diferentes circunstâncias, dentre elas as históricas, sociais, econômicas e culturais, se encontra fragilizado em seu conhecimento sobre o próprio objeto de ensino. E mais: muitas vezes domina muito pouco, ele próprio, as competências de leitura que pretende ensinar. (LEAL, 2006, p.263)

O primeiro item a considerar no guia diz respeito à preocupação com a fundamentação teórica. Todos os capítulos metodológicos iniciam com reflexões sobre a formação do pequeno leitor, juntamente com fundamentos de teoria literária, conceitos (de letramento, leitura compartilhada, mediação, etc.). Na sequência, apresentam exemplos de estratégias, dicas de como conduzir o processo de mediação de leitura, sempre respeitando o caráter das especificidades do gênero tratado, com sugestões de outras leituras para aprofundamento, finalizando cada capítulo com a bibliografia referenciada. Sem contar os volumes dos guia trazem como fundamentos em Bordini (1986, 2007), Lajolo (2001), Zilberman (2003), Soares (2003), Goldstein (2006), Cosson (2014), entre outros. 


\section{Revista de Estudos Acadêmicos de Letras}

Os volumes do guia em questão são os únicos que chegam às salas de aula trazendo um conteúdo realmente formativo, de orientação e aplicação voltadas às necessidades específicas dos alunos em cada ano, de modo particular ao primeiro ano, com a importância do professor como mediador, não só "imputando" a ele essa responsabilidade, como o orientando no processo.

Conta também com chamadas de atenção sobre as atitudes do profissional, conforme observa-se em alguns exemplos selecionados:

Professor, uma boa prática literária não ocorre por acaso. É preciso preparar com antecedência as atividades a serem exploradas: conhecer o livro a ser trabalhado, refletir sobre as possíveis intervenções didáticas a serem realizadas, considerando tanto o que o livro oferece como a realidade sociocultural dos alunos. (p.21, vol. 1, p.22, vol. 2 e p.23, vol.3)

Não realize um fechamento pedagógico de obras abertas.... Convide à fruição. Medeie a leitura atenta e as múltiplas interpretações. E, acima de tudo, não esqueça de se divertir com a turma! Além disso, de acordo com o perfil de cada turma, o trabalho proposto precisa ser modificado, e as provocações do próprio professor ao tomar contato com os livros podem fazer surgir excelentes ideias (ver, quanto a isso, Baldi (2009)). O importante é que você dê vida a esse acervo PNAIC: coloque-o, acima de tudo, a serviço das crianças. (p.52, vol. 1)

A abordagem que o guia traz para a poesia em sala de aula está centrada no lúdico, no jogo de palavras, ressaltando a potencialidade do desenvolvimento literário da criança através do forte apelo sonoro da poesia, elementos que favorecem o letramento literário das crianças. Propõe um trabalho pedagógico que favoreça a apropriação da leitura e escrita como algo significativo e relevante gerando oportunidades que na relação texto-leitor mobilize a "sensibilidade e a afetividade", tomando como dinâmica sugestões que exploram o "Antes da leitura", o "Durante a leitura" e o "Após a leitura". Tudo isso muito bem explicado e valorizando não apenas o processo, mas os ganhos reais com o trabalho do gênero em sala de aula.

Nos capítulos das narrativas, tanto na Prosa, como no capítulo referente aos Livros de Imagens ou nas Histórias em Quadrinhos (HQs), o foco da progressão do trabalho na evolução das etapas escolares é constante. É possível perceber em cada abertura de capítulo uma reiteração de suas concepções de leitura literária, marcadas 


\section{Revista de Estudos Acadêmicos de Letras}

pelo caráter da fruição estética ou nas problematizações oportunizadas pelo imaginar e brincar como caminhos que conduzem na direção do autoconhecimento e do conhecimento de mundo. Tratam de forma pontual os perigos reducionistas da leitura como decodificação e do equívoco da utilização dos "textos como pretextos", defendendo a vinculação da alfabetização ao letramento e "vice-versa".

Os roteiros de práticas de leitura literária propostas nos guias se pautam, primeiramente, na organização de momentos de leitura como rotina escolar. Essas rotinas são divididas em dois momentos: a leitura autônoma e a leitura mediada. Considerando que as crianças do primeiro ano ainda não estão alfabetizadas, a alternativa à leitura autônoma, nessa etapa, é convertida em "escolha autônoma".

Apresentam a leitura autônoma como: “(...) momentos nos quais são privilegiadas as relações entre o leitor e seu livro, aquele que livremente tomou para ler; entre leitor e texto, aquele que, com sua história, este particular leitor fixou por sua singular leitura"(p.46, vol. 1). Sugere-se que esses momentos sejam organizados duas vezes na semana, um completamente autônomo e outro momento também autônomo, mas seguido de compartilhamento. Destaca, ainda, a importância de o professor considerar esse momento para observar as crianças em sua interação com o livro, como cada uma lê, conforme vão se tornando mais íntimos do livro, mais fluentes e experientes na leitura. Dois recados são bem marcados no guia: Um, "ao permitir que a criança circule pelos livros, estamos dando o recado de que a consideramos capaz de selecionar e de ler" (p.44, vol. 1). E o outro, que a sensibilidade do professor para proporcionar esse momento é fundamental, a leitura em voz alta pelos alunos, as rodas de conversas sobre as leituras e sobre as escolhas, tudo são "oportunidades emergentes de ensino-aprendizagem."

Já na leitura mediada, sugere-se que seja uma vez por semana, pondo em evidência a importância da mediação na aprendizagem da leitura literária, o que justifica todo o cuidado com que são dadas as orientações e o detalhamento ao professor sobre cada etapa da mediação. As etapas seguem também as estratégias de "antes da leitura", "durante a leitura" e "depois da leitura", pautadas em Solé (1998), 


\section{Revista de Estudos Acadêmicos de Letras}

apresentadas nas práticas de trabalho escolhidas como exemplo de estratégia, incluindo orientações para o professor que deve não só assumir suas responsabilidades de leitor como atuar na mediação dos textos.

A postura evidenciada na proposta de leitura mediada do guia corrobora com Paiva (2014, p.47) na importância dessa mediação que "[...] desenvolve nos alunos a vontade de expressão, a observação dos modos de contar uma história, assim como é uma atividade professor-aluno que cria vínculo e a vivência de experiências interlocutórias." Da mesma maneira que incentiva o professor a ser também leitor, em processo de interação com os alunos.

Dessa maneira, cabe ao professor estreitar os vínculos entre alunos e obras, buscando, gradativamente, as competências de ambos, o aprimoramento do processo de mediação que, efetivamente, participe e se comprometa com o processo de aprendizagem proporcionado pela literatura. Mesmo na fase de formação inicial do leitor, o professor deve considerar que ler é imergir num universo imaginário, gratuito, porém organizado, carregado de pistas as quais o leitor vai assumir o compromisso de seguir, se quiser levar sua leitura, isto é, seu jogo literário a termo (BORDINI; AGUIAR, 1993, p. 27).

\section{CONSIDERAÇÕES FINAIS}

Procuramos trazer à discussão, neste trabalho, a proposta de leitura literária na alfabetização produzida pela ação do Guia de Literatura na Hora Certa (PNLD/PNAIC -2015). Para perseguirmos nosso objetivo principal, que consistiu em explicitar certos processos de organização presentes nos três volumes que compõem os guias de orientação/formação do professor alfabetizador, buscamos identificar em quais concepções estão ancoradas suas propostas metodológicas, dando visibilidade às representações que projetam sobre o processo de escolarização da literatura na alfabetização e em que medida se vincula ao letramento do professor.

Evidenciou-se, pela análise empreendida, que marcar as séries iniciais como a hora certa da literatura foi o fio condutor da proposta-guia, bastante acentuado nos discursos empreendidos no mesmo. 


\section{Revista de Estudos Acadêmicos de Letras}

Do ponto de vista do processo de formação do professor alfabetizador para o trabalho com a literatura, consideramos uma evolução as abordagens dos guias em sua formatação gradativa, respeitando as fases das crianças e trazendo orientações específicas para cada categoria (versos, prosa, livro de imagens e HQs). Os guias se revelaram uma oportunidade ímpar de sanar a falta de uma formação específica ao docente alfabetizador, uma das causas da abordagem intuitiva da literatura, em sala de aula ou, muitas vezes, apoiados no discurso do não saber fazer acabam por deixála de lado por considerá-la "difícil”, ou ainda, em última instância, por observar apenas o caráter pragmático e utilitarista do texto literário como checagem de decodificação de leitura para o letramento literário.

Ao contrário do se vê em textos instrucionais ou em muitos manuais de orientação pedagógica, a dinâmica discursiva segue pelo envolvimento com o saber proposto, pela sedução e estabelecimento de cumplicidade. Sua abordagem não se reduz ao "cumpra-se", mas ao "porquê" de a literatura ser o melhor caminho e "o que" se pode ganhar no processo se se puser mais atenção e encantamento, no "como" mediar. Motivando o professor a ser também leitor para que assim possa atingir melhor o letramento do aluno.

\section{Referências}

BORDINI, Maria da Glória; AGUIAR, Vera Teixeira de. Literatura - a formação do leitor: alternativas metodológicas. 2. ed. Porto Alegre: Mercado Aberto, 1993.

BRASIL. Secretaria de Educação Básica. Diretoria de Apoio à Gestão Educacional. Pacto nacional pela alfabetização na idade certa: currículo na alfabetização: concepções e princípios: ano 1: unidade 1/Ministério da Educação. Secretaria de Educação Básica, Diretoria de Apoio à Gestão Educacional. - Brasília: MEC, SEB, 2012.

- Literatura na hora certa: guia 1: $1^{\circ}$ ano do ensino fundamental: PLND/PNAIC Alfabetização na hora certa 2015 / Ministério da Educação, Secretaria de Educação Básica. Brasília: MEC/SEB,2015a.

- Literatura na hora certa: guia 2: $2^{\circ}$ ano do ensino fundamental: PLND/PNAIC Alfabetização na hora certa 2015 / Ministério da Educação, Secretaria de Educação Básica. Brasília: MEC/SEB,2015b. 


\section{Revista de Estudos Acadêmicos de Letras}

Literatura na hora certa: guia 3: $3^{\circ}$ ano do ensino fundamental: PLND/PNAIC Alfabetização na hora certa 2015 / Ministério da Educação, Secretaria de Educação Básica. Brasília: MEC/SEB,2015c.

BAZZO, J. L. S. MUSA, M.L.N. Literatura infantil e juvenil na formação do professor alfabetizador: ou PNAIC na berlinda? Anais $6^{\circ}$ Seminário de Literatura Infantil e Juvenil-SLIJ. Florianópolis: UFSC; UNISUL,2014a. P. 362-370.

BAZZO, J.L.S.; CHAGAS, L. M. M. Leitura de fruição no programa nacional de alfabetização na idade certa no Estado de Santa Catarina. Revista Linha Mestra, Campinas, SP, ano 8, n. 24, p. 144-162, jan./jul. 2014b.

DOMINGUES, Chirley. A hora e a vez da literatura infantil como parte significativa da formação do professor: experiências do PNAIC. In: Anais $6^{\circ}$ Seminário de Literatura Infantil e Juvenil-SLIJ. Florianópolis: UFSC; UNISUL,2014. p. 124-130.

EVAnGEliStA, A. A. M.; BRANDÃO, H. M. B.; MACHADO, M. Z. V. Escolarização da leitura literária. 2. ed. Belo Horizonte: Autêntica, 2001.

LEAL, Leiva de Figueiredo Viana. Leitura e formação de professores. In: EVANGELISTA, Aracy Alves Martins et al. Escolarização da leitura literária. 2. ed. Belo Horizonte: Autêntica, 2001.

PAIVA, A. MACIEL, F. Discursos da paixão: a leitura literária no processo de formação do professor das séries iniciais. In.: PAIVA, A. et. al. Leituras literárias: discursos transitivos. 1 ed. $1^{\mathrm{a}}$ reimpressão. Belo Horizonte: Ceale/Autêntica, 2008.

PAIVA, Ana Paula. Livros de imagem: Como aproveitar a atratividade e desenvolver o potencial dessas obras na sala de aula com atividades literárias. In: Centro de Alfabetização, Leitura e Escrita da UFMG (org.). PNBE na Escola: Literatura fora da caixa. Guia 1. Educação Infantil. Brasília: Ministério da Educação, Secretaria de Educação Básica, 2014. p. 45-60.

PAULINO, Graça; PINHEIRO, Marta Passos. Ler e entender: entre a alfabetização e o letramento. Revista Estudos, v. 2, n. 2. Belo Horizonte: Uni-BH, 2004.

Algumas especificidades da leitura literária. In: PAIVA, Aparecida et al. (Orgs.). Leituras literárias: discursos transitivos. Belo Horizonte: Ceale; Autêntica, 2005. p. 55-70.

RESENDE, V.A.D.de R. Análises dos pressupostos de linguagem nos cadernos de formação em Língua Portuguesa do Pacto Nacional pela Alfabetização na Idade Certa-PNAIC. 2015. 216 f. Tese (Doutorado em Educação) Unesp, São Paulo. 2015.

SOARES, M. B. A escolarização da literatura infantil e juvenil. In: EVANGELISTA, A. A. M.; BRANDÃO, H. M. B.; MACHADO, M. Z. V. Escolarização da leitura literária.2. ed. Belo Horizonte: Autêntica, 2001.

SOUZA, Renata Junqueira; COSSON, Rildo. Letramento literário: uma proposta para sala de aula. Caderno de Formação: formação de professores, didática de conte údos. São Paulo: Cultura Acadêmica, v. 2, p. 101-10, 2011. 
SOUZA, R.J.; SILVA, K. A de A. M.; ARIOS, C. F. A Leitura e a Função da Literatura no PNAIC: para Além do Deleite. Educação em Revista: Marília, v.17, p. 63-80, 2016.

ZILBERMAN, Regina. A leitura e o ensino da literatura. Curitiba: InterSaberes, 2012. 